\title{
El exilio republicano español en Repertorio Americano ${ }^{1}$
}

\section{The Spanish Republican Exile in Repertorio Americano}

\section{O exílio republicano espanhol no Repertório Americano}

\author{
Dra. Angélica López-Plaza \\ Becaria posdoctoral \\ Centro de Investigaciones sobre América Latina y el Caribe \\ Universidad Nacional Autónoma de México \\ México \\ Recibido: 31 de agosto 2016 \\ Aceptado: 17 de enero 2017
}

\section{Resumen}

Se analiza la revista costarricense Repertorio Americano para encontrar en sus textos la propuesta política que proclamaron los refugiados españoles. Se hace especial énfasis en aquellas figuras que geográficamente se encontraban en Costa Rica. Asimismo, se interpreta el texto de la revista a partir de la coyuntura histórica en la que se produce, así como el campo cultural en el que se inscribe. La investigación

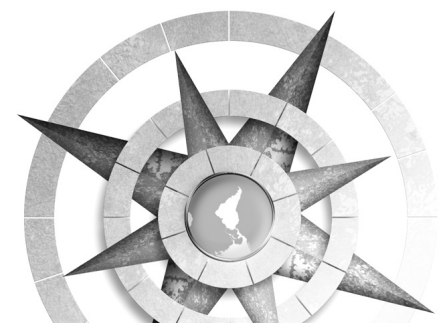

intenta abrir nuevas rutas de acercamiento a lo que ha sido, hasta el momento, el análisis y el estudio del exilio republicano español en Centroamérica.

Palabras clave: exilio republicano español; Repertorio Americano; Costa Rica; Joaquín García Monge, Temas de Nuestra América.

\section{Abstract}

The Costa Rican journal Repertorio Americano is analyzed to find in it the political proposal Spanish refugees proclaimed.

1. El presente análisis es producto del proyecto de investigación posdoctoral que llevo a cabo en el Programa de Becas Posdoctorales en la UNAM, como Becaria del Centro de Investigaciones sobre América Latina y el Caribe. 
Special emphasis is placed on those figures who geographically were living in Costa Rica. Likewise, the journal text is interpreted both from the perspective was produced, and from the cultural field it belongs to. The research intends to of the historical conjuncture in which it open new ways to approach what has been so far the analysis and study of the Spanish republican exile in Central America.

Keywords: Spanish Republican exile, Repertorio Americano, cultural journals of Costa Rica, Joaquín García Monge, Temas de Nuestra América

\section{Resumo}

A revista costarriquense Repertório Americano é analisada para encontrar em seus textos a proposta política proclamada pelos refugiados espanhóis. Estas análises se enfatizam, de forma especial, aos personagens que geograficamente estavam na Costa Rica. Além disso, o texto da revista é interpretado a partir do contexto histórico em que ela ocorre, e também o contexto cultural em que está marcada. A pesquisa tenta abrir novas vias de abordagem para o que tem sido até agora a análise e o estudo do exílio republicano espanhol na América Central.
Palavras chave: exílio republicano español, Repertorio Americano, revistas culturais de Costa Rica, Joaquín García Monge, QuestÕes de Nossa America

\section{Introducción}

Es conocida la importancia de la labor de los exiliados españoles en distintas esferas de la vida intelectual, cultural y científica en América Latina. La difícil y, a veces, utópica integración en un nuevo espacio, la reflexión velada de la política, sobre todo, desde una experiencia de desarraigo, así como los silencios elocuentes y las mitificaciones por parte de la crítica revelan zonas susceptibles de nuevas miradas y de acercamientos novedosos. A pesar del cúmulo de aportaciones que acrece el material bibliográfico sobre el exilio republicano español en nuestra América, todavía encontramos ciertos vacíos críticos relacionados con la carga política del fenómeno propio del exilio y su contextualización cultural e intelectual en los diferentes lugares de acogida.

El exilio republicano español en México ha sido uno de los más estudiados por críticos literarios, sociólogos e historiadores. México es, sin duda, el país en el cual se han realizado los estudios más sustanciales y abundantes sobre la emigración española. La bibliografía 
sobre el tema da cuenta de la abundancia, pluralidad y riqueza de esas publicaciones. Con todo, una de las regiones geográficas menos atendida por los investigadores avocados al estudio de este fenómeno histórico, político y cultural ha sido Centroamérica, particularmente el caso de Costa Rica. Al igual que en el caso mexicano, en Centroamérica se dieron gestos de solidaridad con la causa republicana, que se tradujeron en la formación de distintas redes intelectuales. En este panorama, las revistas constituyeron los foros de sociabilidad más importantes para la circulación de ideas, de visiones artísticas y posturas políticas. Los proyectos hemerográficos creados por los exiliados en distintos países latinoamericanos han sido explorados mucho y bien por diversos autores ${ }^{2}$. Sin embargo, uno de los aspectos más reveladores, y el menos atendido por la historiografía acerca del éxodo español, corresponde a la asidua participación y colaboración de este grupo de escritores, artistas, pedagogos y políticos en distintas revistas

2 Entre la bibliografía más importante sobre la prensa del exilio republicano español en América Latina se encuentra: Abellán, J. L. (1996). La revista España Peregrina como paradigma del exilio español de 1939. Archipiélago: Cuadernos de crítica de la cultura, número, 26-27, pp. 119-124; Caudet, F. (1992). El exilio republicano en México. Las revistas literarias (1939-1971). Madrid: Fundación Banco Exterior; González Neira, A. (2010). Prensa del exilio republicano 1936-1977. Santiago de Compostela: Andavira Ed.; Rojo, G. y Valender, J. (1999). Las Españas: historia de una revista del exilio. México: El Colegio de México. coordinadas y dirigidas por sus homólogos americanos.

Si pensamos la textualidad de los proyectos hemerográficos desde una perspectiva transatlántica entonces podríamos preguntarnos: ¿cómo se altera el pensamiento político del exiliado al llegar a tierras americanas? ¿Qué imágenes arrastra su discurso y qué ausencias evoca? Así, las revistas constituyen las coordenadas necesarias por las que podemos trazar las distintas redes intelectuales, los proyectos culturales y políticos que se difundieron durante el éxodo español en Centroamérica.

En este orden de ideas, propongo analizar la revista costarricense Repertorio Americano y encontrar en sus textos la propuesta política que proclamaron los refugiados españoles. Se hace especial énfasis en aquellas figuras que geográficamente se encontraban en Costa Rica. Asimismo, se interpreta el texto de la revista a partir de la coyuntura histórica en la que se produce así como el campo cultural en el que se inscribe. La investigación intenta abrir nuevas rutas de acercamiento a lo que ha sido, hasta el momento, el análisis y el estudio del exilio republicano español en Centroamérica. 


\section{Un acercamiento a Repertorio Americano}

Dirigida por Joaquín García Monge, la revista Repertorio Americano, aparecida en San José, Costa Rica, en 1919, de publicación semanal (aunque con algunos periodos irregulares) fue un proyecto de largo alcance dedicado a la cultura hispánica. Entre septiembre de 1919 y mayo de 1958, se publicaron aproximadamente mil números. Filosofía, literatura, arte, educación y ciencias son algunas de las disciplinas que el semanario incluyó entre sus páginas. Continuadora en cierto modo de Repertorio, revista fundada por Andrés Bello en 1826, el nuevo semanario tuvo el propósito principal de aglutinar a los escritores americanos en un frente común que enfatizara un tono de alianza hispanoamericana.

En las páginas de la revista encontramos colaboraciones de destacados representantes de la vida intelectual y literaria de América Latina y España, por ejemplo: Miguel de Unamuno, Gabriela Mistral, José Carlos Mariátegui, Alfonso Reyes, José Ortega y Gasset, Víctor Raúl Haya de la Torre, Mario Sancho, Ricardo Segura, Emilia Prieto. La revista se perfiló entonces como un eslabón importante en la articulación de un proyecto cultural hispánico entre América y la Península. Así lo muestran los ensayos, los poemas, las notas y las cartas que durante treinta y nueve años se publicaron. De hecho, la presencia de los peninsulares en el Semanario no se limita únicamente a sus colaboraciones, también ejercieron un papel fundamental en su producción y confección. Avelino Alsina y José Borrasé, catalanes residentes en Costa Rica desde principios del siglo XX, fueron los impresores que se ocuparon de la edición de cada uno de los números (Oliva, 2008 ${ }^{a}$.

Ahora bien, el detonante que contribuyó a consolidar la cultura hispánica vertida en las páginas de la revista fue el inicio de la guerra civil española (1936-1939). El tema de España, desde el comienzo del conflicto bélico, tuvo un notable auge entre los escritores agrupados en torno a Repertorio Americano. En sus páginas encontramos manifiestos, poemas, ensayos y reflexiones políticas de autores españoles y latinoamericanos a favor de la Segunda República. Abundan los homenajes a Federico García Lorca, a Antonio Machado y al Quijote de Cervantes. Entre los costarricenses que delinearon las dimensiones éticas del conflicto español encontramos la poética de Carlos Luis Sáenz y Ricardo Segura, y el ensayo político de Mario Sancho 
y Vicente Sáenz $z^{3}$, solo por mencionar algunos. Repertorio Americano se convirtió en el órgano de difusión de la causa republicana española en un ambiente político y social muy poco favorable. El gobierno costarricense presidido por León Cortés (1936-1940), de ideología conservadora y anticomunista, ofreció una marcada dualidad entre la posición neutral exhibida de cara al sistema internacional y las simpatías y apoyo que en el nivel nacional mostró por los franquistas ${ }^{4}$. Asimismo, diversos grupos católicos costarricenses se mostraron activa y apasionadamente en favor del general Francisco Franco. En las páginas de la revista se registró la actitud que el gobierno mostró hacia la ayuda diplomática que algunos países latinoamericanos brindaron a los españoles. A este respecto, sobresale el incidente diplomático chileno-español.

En plena contienda bélica, la embajada chilena en Madrid acogió a diecisiete españoles republicanos que se vieron amenazados por los sublevados. Desde suelo peninsular, la Embajada solicitó ayuda internacional para evacuar a los refugiados. A este respecto, el gobierno

3 Véase para mayor detalle la obra de Mario Oliva Medina (2008b) , Los intelectuales y las letras centroamericanas sobre la guerra civil española, México:UNAM/CIALC.

4 Véase el artículo de Rosa Pardo Sanz (1990) para un análisis en detenimiento de la postura del gobierno costarricense a favor del franquismo. de Costa Rica guardó silencio. Edgar Odio González (1939) comentó en las páginas de la revista el sensible desacierto del gobierno de León Cortés: "por no intervenir en los asuntos de España, se abstiene de pronunciarse sobre los refugiados republicanos en la Embajada de Chile en Madrid" (pp.244-245).

Con todo, y pese a la postura oficial del gobierno, la solidaridad hacia las gestiones diplomáticas chilenas no se hizo esperar: "estamos con Chile porque Chile defiende la decencia. El mundo dirá un día que fue la Embajada Chilena en Madrid en donde se dio el primer grito a favor de la cruzada por la decencia". (Del Camino, 1939: 272). El silencio del presidente León Cortes respondió sobre todo al apoyo que ya en abril de 1939 había brindado al general Franco.

Una vez concluida la guerra civil española, el gobierno costarricense incrementó la política a favor del franquismo. En 1940, el Ministro de Relaciones Exteriores de Costa Rica manifestó su negativa a recibir refugiados republicanos:

El gobierno ha seguido, en materia de inmigración, una política definida y rígida en lo que se refiere a la inmigración inconveniente e indeseable y, en consecuencia, habrá que aplicarla inflexiblemente ante cualquier intento que se haga para el ingreso en el 
país de los emigrados españoles poco deseables por diversos conceptos (Pardo Sanz, 1990: 169).

La declaración da cuenta de la postura oficial que mantuvo el gobierno con respecto al asilo de los republicanos españoles. Sin embargo, la política exterior del gobierno costarricense presentó ciertas fisuras. Durante la década de 1940 llegaron a suelo costarricense refugiados españoles con diversos perfiles académicos, profesionales y políticos. Entre las figuras más destacadas encontramos al biólogo Rafael de Buen Lozano, el profesor y agrónomo Víctor Lorz y Lizárraga, el médico Rafael Ruano Riesgo y el poeta León Felipe. La travesía de estas figuras en la vida cultural quedó plasmada en las páginas de Repertorio Americano. Asimismo, colaboraron en la revista figuras de renombre internacional como Juan Ramón Jiménez, José Moreno Villa, José Bergamín, Benjamín Jarnés, Agustí Bartra, David García Bacca, entre otros.

\section{Al vagar de una pluma bohemia y otros textos}

Víctor Lorz y Lizárraga fue el republicano español, refugiado en Costa Rica antes de que concluyera el conflicto bélico, que con mayor conciencia crítica se dedicó a reflexionar sobre la causa republicana y las consecuencias del franquismo. Las reflexiones que hizo el profesor y agrónomo español corresponden a dos propósitos fundamentales: primero, ofrecer una interpretación de la guerra civil desde una perspectiva anticlerical; segundo, comentar la situación de España en el marco de la política internacional. Cada una de las entregas que Víctor Lorz y Lizárraga hizo a la revista se distinguió por un tono crítico e incisivo.

"Al vagar de una pluma bohemia", "Divagaciones de una pluma errante" y "Ocios mentales" son los tres títulos que reúnen casi todas las colaboraciones del profesor español en Repertorio Americano. Los títulos caracterizan en buena medida la identidad del que escribe: un refugiado político que plantea su escritura como una errancia, un ir y venir sin hallar camino. Así pues, el acto de escribir representa un lugar privilegiado de indagación sobre la propia identidad. Con todo, la metáfora del deambular de la escritura se contrapone a la necesidad que tiene el escritor de aferrarse a España. En una carta que encabeza uno de sus ensayos, Víctor Lorz (1939: 196) explicaba a Joaquín García Monge cuáles habían sido las razones para la elección del título: "Como usted verá, mi pluma es de marca bohemia. Va de acá para allá; sin domicilio de tareas fijo; posándose en todo lo que encuentra, como una 
mariposa de acero; pero, ensartando en sus puntas todos los bichos que encuentra a su paso”.

Con todo, la principal punta de lanza de la crítica de Víctor Lorz iba dirigida a la injerencia que tuvo la Iglesia católica en el conflicto español. Un mes antes de que concluyera la guerra civil, el profesor denunciaba la falange española como principal responsable de los sangrientos hechos ocurridos en la Península:

En esta hora terrible, el crimen y los veinte dineros de Judas, están con ellos. Ellos beben, engordan y ríen, mientras nosotros, hijos de la ley, tenemos el alma acongojada y desgarrada por el dolor infinito de nuestra santa España. Pero sepan los obispos y los frailucos politiqueros, que la República española, que no ha hecho mal a nadie ha de ser terriblemente vengada. Y que, algún día, la han de llamar a gritos para que vuelva. Pero ya no volverá tan mansa con los obispos y los frailes politiqueros. ¡La sangre de dos millones de seres humanos, no se derrama en vano! La España que venga no será la vuestra. La que vosotros soñasteis, al echarnos en brazos de esos forajidos inconmensurables de la falange española (Lorz y Lizárraga, 1939a: 187).
Las declaraciones de Víctor Lorz responden a la postura anticristiana que tomó la alta jerarquía de la Iglesia católica al apoyar el levantamiento militar del general Franco. Recuérdese que las reformas discutidas en el escenario de las Cortes Constituyentes en los últimos meses de 1931, particularmente las clausulas dirigidas al sector religioso - aquellas que declaraban la no confesionalidad del Estado, eliminaban la financiación del clero, introducían el matrimonio civil y el divorcio, y prohibían el ejercicio de la enseñanza a las órdenes religiosas, entre otras - provocaron una oleada de reacciones adversas al régimen. Con la proclamación de la $\mathrm{Re}$ pública, la Iglesia perdió, o sintió que perdía, una buena parte de su posición tradicional, identificada sobre todo con el conservadurismo político y el orden social. Durante los primeros años del gobierno republicano se hizo patente el fracaso de la Iglesia y de algunos de sus ministros para comprender los problemas sociales y los nuevos cambios en materia política y económica.

En este panorama de tensiones y desacuerdos surgió el partido político Falange Española, fundado en 1933 por José Antonio Primo de Rivera. El 15 de febrero de 1934, la Falange Española se fusionó con las Juntas de Ofensiva Nacional-Sindicalista (JONS), fundadas por Onésimo Redondo y Ramiro Ledesma Ramos, entre otros. 
El nuevo partido se denominó Falange Española de las JONS (FE de las JONS). Así, la falange y la Iglesia católica constituyeron los dos pilares fundamentales del franquismo en la Península y en Latinoamérica.

La posición política de Víctor Lorz y Lizárraga tuvo, durante la década de los años cuarenta, importantes transformaciones. Sus colaboraciones en la revista fueron respuestas, generalmente coyunturales, para intentar orientar la visión que se tenía en el exilio de la problemática de España. De modo que en sus reflexiones acerca del antifranquismo también tuvo presente el caso de América Latina. Durante el primer año del exilio republicano español en Centroamérica el falangismo cobró un auge insospechado. El apoyo de sectores conservadores fue decisivo para la difusión de las ideas imperiales del grupo pro franquista. Entre las personalidades costarricenses que se destacaron por su apoyo a los falangistas encontramos a J. N. Pinaud, director de La Tribuna y a D. Rafael Soley, titular del diario Novedades, ambos vinculados al Comité Patriótico Español. Víctor Lorz (1942a) hizo referencia a estos hechos:

Pero es una insigne torpeza agitar aquellos temas en América, ya que, al trasluz de la retórica falangista, se adivina la intención de sembrar el problema sudeté en el suelo ame- ricano, como anticipo de la cosecha política que advendría después: incorporación de América a España. A mí no me extraña que, en la España nazi, donde no hay libertad para nada, la haya, no obstante, para hablar descaradamente de imperio. Lo que no alcanzo a comprender es, que América se preste a ser un ateneo en que se ventile alegremente el problema sudeté de España. Esto es un abuso de la hospitalidad que debía ser resuelto por la policía con un plazo de veinticuatro horas.

El alma de América no está cerrada para nadie. Tampoco está abierta para uno solo. Antena levantada en los espacios libres, recoge de todos los rumbos de la rosa náutica el Alma Universal.

No solo Víctor Lorz se expresó acerca del franquismo en Latinoamérica, también el biólogo y oceanógrafo español Rafael de Buen Lozano publicó en la revista un ensayo sobre los acontecimientos políticos que en el nivel internacional se dirimían. El devenir de la Segunda Guerra Mundial y la posición neutral que la mayoría de los países latinoamericanos tuvo durante los primeros años del conflicto bélico fue motivo de reflexión para los exiliados españoles en Costa Rica. El avance del nacional-socialismo, impulsado por Adolf Hitler, y la posibilidad del dominio mundial alarmaron al biólogo español: 
América ha podido vivir hasta ahora alejada del estruendo de las batallas y de la destrucción y muerte que caracterizan a los bárbaros métodos utilizados por el nacismo y sus satélites. El aislamiento no ha permitido que se dé el Nuevo Continente exacta cuenta de los peligros que le acechan y de los resultados catastróficos que traería consigo la victoria hitlerista. Por ello la primera tarea que se plantea es el de enseñar la verdad a todos aquellos que, por desconocimiento de la realidad o por falta de cultura política, pueden ser inconscientemente un elemento peligroso a manos de los agentes de la quinta columna.

Hay que pensar en que todos debemos ser combatientes y estar preparados para empuñar las armas si fuera necesario (De Buen Lozano, 1942).

La idea de empuñar las armas expresada por Rafael de Buen Lozano fue una noción que también compartió Víctor Lorz. Según el profesor español, una de las razones que favoreció la derrota de la Segunda República fue precisamente la falta de armamento y de capacitación militar. En un ensayo titulado Recuerdos y esperanzas, Víctor Lorz elogia el carácter idealista de los filósofos e intelectuales que crearon la República en 1931, pero desaprue- ba la falta de experiencia militar que tuvo la Península para enfrentar a los sublevados. En el ensayo se expresa la esperanza de la creación de una tercera República más justa y democrática, pero también menos inocente:

Y aprendamos para el futuro. Que no nos cojan otra vez de primos Para que, cuando amanezca la tercera República, que sea en buena hora democrática, cada vez más democrática, más del pueblo, todo para el pueblo. Que venga acompañada de todos los dones excelsos: el cuerno de la abundancia como Pomona, y los resplandores del espíritu, como Minerva. Pero que no sea tonta otra vez. Que en los rincones del Olimpo no deje olvidada las armas. Y que traiga bajo el brazo su casco y su lanza como la diosa griega (Lorz y Lizárraga, 1942b).

Asimismo, el médico español Rafael Ruano Riesgo publicó en Repertorio Americano un discurso pronunciado en el Colegio de San Luis Gonzaga, en Cartago, Costa Rica, en el cual expresaba su opinión sobre la guerra de España y sus consecuencias en el conflicto bélico mundial. Ruano hacía especial énfasis en cuál debía ser la conducta y el deber de los refugiados españoles en el exilio: 
Es un deber para todo republicano español y para todo hombre honrado, proclamar en voz alta, allí donde se encuentre, la verdad sobre los motivos de la guerra española y la verdad sobre el exilio español. Es un deber sagrado para todo republicano español y para todo hombre libre del mundo, hacer ver al resto de la humanidad que los republicanos españoles lucharon ardientemente por un mínimo de libertades burguesas y no por la implantación de ningún régimen comunista (Ruano Riesgo, 1943).

Como hemos analizado hasta el momento, los ensayos escritos por los exiliados españoles van dirigidos a explicar los acontecimientos de la guerra civil y la situación que vivía España en el nivel internacional. Los ensayos expresan en general una firme convicción en un nuevo orden político y moral. La nostalgia, común en la mayor parte de las aportaciones literarias y políticas de los exiliados, no forma parte de las reflexiones de estos ensayistas. La determinación de dar continuidad en el exilio a los valores republicanos defendidos durante la Guerra Civil tiene que leerse como una acción emprendida en contra de los que en el ámbito internacional rechazaban las ideas progresistas y democráticas de la Segunda República.
Ahora bien, pese a que los ensayos políticos se orientan en una sola dirección, esto es, la causa republicana, las diferencias en cuanto a los temas son importantes. Víctor Lorz, por ejemplo, se declara fiel creyente de la política rusa. Algunos de sus ensayos se destacan por un tono bastante apasionado por el nuevo orden que en materia política e ideológica dictaba la URSS. Según él, Rusia encarnaba la solución a los problemas trascendentales del hombre, esto es, "la relación entre el ser y el pensar, entre la realidad y la religión” (1943). Y sobre el socialismo añadía:

El socialismo nos purifica de egoísmo, enseñándonos a declinar el yo en función del nosotros, que es más noble, más fraternal, más democrático, y de un carácter moral y religioso incomparablemente más elevado.

Creo en Rusia. Creo que ella guarda el secreto de la paz futura. Creo que la fórmula de esta paz es el socialismo, la cooperación (Lorz y Lizárraga, 1944).

Con todo, y pese a las esperanzas de una paz futura encarnada en el ejemplo ruso, a finales de la década de los años cuarenta las colaboraciones de los exiliados, particularmente en lo referente al antifranquismo y la situación política 
española en el nivel internacional en las páginas de Repertorio Americano, mermó considerablemente. Los exiliados creyeron que una vez derrotadas las fuerzas del Eje, los aliados intervendrían para derrocar el franquismo.

Pese a los augurios de una solución diplomática apoya en el seno de la Asamblea de las Naciones Unidas, las sanciones impuestas al régimen franquista fueron levantadas. En 1950 comentaba con un tono irónico la situación desfavorable que el tema de España tenía en el contexto mundial: "Franco no está solo. Quemar libros o cerrar las aduanas para ciertas ideas, ¿qué más da? No importa que en la Asamblea General de la UNO y en la sesión del 6 de septiembre de 1948, hayamos hecho la Declaración Universal de los Derechos del Hombre...”. (Lorz y Lizárraga 1950a).

Pese al drama político que en el ámbito internacional se vivía, Víctor Lorz siempre mantuvo su mirada puesta en el futuro, aunque sin olvidar su lugar de origen y la causa que defendía. Así, en una de las últimas colaboraciones a Repertorio Americano, el profesor español confesaba su pasión por los románticos europeos. La metáfora sobre las ruinas y el pasado lo ayudaban a ubicar su presente:
Amo lo antiguo: lo que fue; lo que está muerto. Como Schiller, Bécquer, France y los románticos gusto de andar y meditar entre ruinas. No me sería posible vivir sin el Pasado. Este se abre ante mi alma como un panorama infinito de luz y sabiduría. Por grande que él sea, ¿qué valor tiene el presente si sólo es una pesadilla entre dos nadas, o un momento fugaz?

¿Se puede vivir sin el futuro? ¿Se puede vivir sin soñar? Quizás no (Lorz y Lizárraga, 1950).

Ahora bien, lo que tal vez se eche de menos en las colaboraciones de los exiliados es la referencia explícita a Costa Rica. Los ensayos, como hemos señalado, en general giraban en torno a la problemática española. Sin embargo, los acontecimientos políticos en el país centroamericano también tuvieron un sino trágico. En 1948, se desata la guerra civil, mejor conocida como la Revolución del 48. El conflicto bélico (marzo a mayo de dicho año) fue el reflejo del nuevo alineamiento de fuerzas sociales y políticas en diversos sectores de la sociedad costarricense. De estos hechos surgen figuras tan importantes para el desarrollo de la política centroamericana y caribeña como José Figueres. De ahí que sea tan sintomático el silencio y la distancia que en materia política mantuvieran los exiliados. 
Sin embargo, como se ha demostrado en diversas investigaciones sobre el exilio: "una de las consecuencias más trágicas de vivir y trabajar dentro de una comunidad nacional que no es la propia es una agudización de la frontera entre el pensamiento y la acción o, en el caso del intelectual entre las ideas y la participación política” (Faber, 2005: 375). De esta forma, los refugiados españoles en Costa Rica desarrollaron un perfil intelectual vinculado a un tema muy concreto y específico: la problemática de España. En las reflexiones de los colaboradores españoles la política del país de acogida quedaba implícitamente censurada.

Con todo, pese a la distancia que mantuvieron en lo referente a la política costarricense (y quizás por esa misma razón), los exiliados -Víctor Lorz y Lizárraga, Rafael de Buen Lozano, Rafael Ruano Riesgo- se destacaron en sectores como la educación y la salud. Un buen ejemplo de la estabilidad laboral, social y económica que los desterrados experimentaron al llegar a Costa Rica es el testimonio de Rafael de Buen Lozano. Él escribió a su hija desde San José informándole de su situación en el país centroamericano:
Sigo mis trabajos como siempre, además de mi labor en la Universidad y en salubridad, me estoy ahora ocupando de cuestiones de pesca y también tengo que dedicar mucho tiempo a los trabajos relacionados con nuestra lucha en relación con España. Colaboro con todas las asociaciones antitotalitarias, en las organizaciones de republicanos españoles. De manera que no tengo ni un momento libre. También recibo muchas revistas y periódicos nuestros, que leo con el interés que puedes figurarte en la dicha de estar enterado de todo lo que se hace en América. [...]No me ha sentado mal mi instancia en estas tierras, desde luego me he repuesto mucho desde que llegue, después de la guerra en España y las fatigas en Argelia, necesitaba un período de buena alimentación y la tranquilidad (En: Tarracena, 2015: 107).

La cómoda estadía de Buen Lozano en Costa Rica e incluso la libertad que tuvo para realizar trabajos propagandísticos a favor de la República fue un hecho generalizado en la comunidad de los refugiados. Por ejemplo, el doctor Rafael Ruano Riesgo fue el jefe de la Unidad Sanitaria de Tres Ríos, así como de las sucursales del Seguro Social de Puntarenas y Limón y secretario médico de la Dirección Médica. De igual forma, 
Víctor Lorz y Lizárraga trabajó como profesor de diversas materias en la Universidad Nacional ${ }^{5}$.

\section{El caso de León Felipe}

En este punto convendría destacar la breve estadía del poeta León Felipe en Costa Rica, quien fue invitado por Mario Sancho a dictar una serie de conferencias. León Felipe llegó al país centroamericano en junio de 1946. Joaquín García Monge tuvo muy presente el arribo del escritor al país. El caluroso recibimiento que los jóvenes estudiantes y poetas costarricenses brindaron al bardo del éxodo español, quedó plasmado en las páginas de Repertorio Americano.

Entre los textos dedicados al autor de Ganarás la luz encontramos la presentación de Guillermo Aguilar Machado, director del Conservatorio Nacional de Música, las notas de Carlos M. Castillo y de Corina Rodríguez, los poemas de Emma Gamboa y Arturo Agüero Chaves y la ilustración de Francisco Amighetti. Cada uno de los textos comenta, aunque con distintos tonos y matices, la estética del poeta. Asimismo, se pone especial énfasis en uno de los temas fundamentales de su obra: la necesidad de situar el problema

5 Véase Amo, Julián y Shelby Charmion (1959). La obra impresa de los intelectuales españoles en América (1936-1945). California: Standford University Press. de España dentro de una noción más amplia y trascendental sobre la condición humana. Emma Gamboa (1946: 232) lo describe como un poeta sin fronteras ni partidos, como un poeta del Hombre:

León Felipe, este poeta del éxodo, peregrino de la España fiel a su destino, este poeta de España y de la España resucitada, como él dice, en América, es el poeta rebelde en clamor de la Luz.

Sus palabras rompen la tiniebla con una lágrima de fuego.

Poeta de la Luz, única manera de clasificarlo.

No es el poeta del pobre ni del rico, del industrial o el proletario.

Es el poeta por la justicia sin clase, ni fronteras. Es el poeta que cree en Dios y con Dios habla, a su manera.

Poeta sin fórmulas ni partidos.

Poeta del Hombre.

Hombre él mismo.

Asimismo, Corina Rodríguez (1946: 233) destacó la importancia del grupo de escritores y artistas costarricenses reunidos en torno al movimiento Pro República Española cuando señalaba: "el poeta debe saber, que en esta pequeña 
patria, los que formamos el grupo Pro República Española, los izquierdistas, los artistas y los hombres honrados, oyeron el grito estridente de España cuando Franco le asestó una puñalada casi al nacer". La nota enfatiza el apoyo que ciertos sectores del campo cultural e intelectual costarricense brindaron a la causa republicana desde el inicio del conflicto bélico.

El homenaje a León Felipe ejemplifica muy bien la política cultural de Repertorio Americano. Como ya habíamos señalado, la orientación política de la revista consistió en una exaltación de la cultura hispanoamericana y, en este sentido, la llegada de algunos refugiados españoles a suelo costarricense contribuyó a consolidar el eje fundamental del proyecto.

Por otra parte, resulta sumamente significativa la carta que León Felipe envió a Joaquín García Monge antes de su llegada al país centroamericano:

Mi querido amigo: Aquí me tiene Ud., en El Salvador. Voy hacia la Argentina. Al principio pensé hacer el viaje de un tirón... Luego he organizado mis cosas para conocer toda la América española, i no paso a paso, por lo menos con el reposo que permiten hoy los aviones.
Creí que traía en mi portafolio algunas cosas poéticas que enseñar -perdónenme esta vanidad de europeopero a cada paso que doy me guardo mis papeles y me dedico a escuchar y a aprender...

No quiero pasar sin verles a Uds. Costa Rica es ya para mí un país de Leyenda sencilla, donde la vida, me dicen, se recoge de un manera patriarcal y familiar... Los pueblos lugareños ayer, se hacen metrópolis babélicas, y uno anda ya buscando rincones donde hablar sin prisas de cosas tan inútiles y esenciales como la Poesía.

Si me dan hospitalidad, estaré ocupado con Uds. una semana. No me concedieron la visa en el pasaporte todavía. En Guatemala llené un esqueleto y cuyo visto bueno espero encontrar en El Salvador (Hotel Lido o Universidad). Acuda Ud. en mi favor para que no pase lo de hace diez años. Diga Ud. que soy un hombre pacífico, que no he tenido jamás carnet de ninguna clase y que no pertenezco a ninguna parroquia ni cofradía... Que no tengo intención de asesinar al Presidente... Llevo un poco de amor... y busco un poco de amor nada más... Es todo mi equipaje político. Con él he estado diez días en Guatemala. Ahora permaneceré aquí hasta el próximo sábado... en 
Managua me quedaré toda la otra semana... Y, si Uds. me dejan entrar a su casa, dentro de 15 días llamaré con mi bordón a la puerta...

[...] Me lleno de regocijo al pensar que voy a ver y a abrazar a amigos tan buenos y queridos como Ud. y Mario Sancho y su familia. Les mando por adelantado un abrazo cordial (1946: 233).

El poeta ofrece los detalles de su viaje por América Latina y recuerda la situación que en la década de los años treintas vivó en Centroamérica. En aquella época, León Felipe había emprendido un viaje por Guinea, México, Estados Unidos y Panamá. A las pocas semanas de declararse la guerra civil española, él se encontraba en la región centroamericana. Antes de abandonar el país escribe Good bye, Panamá. El texto, que debía ser transmitido por las estaciones de radio, iba dirigido a los españoles residentes en Panamá que apoyaban el levantamiento militar. Esta situación provocó algunas diferencias entre el poeta y los sectores centroamericanos conservadores. Sin embargo, su arribo a Costa Rica, como se ha analizado, tuvo una gran repercusión en los jóvenes escritores.

Como hemos visto, Repertorio Americano fue una revista concebida como un lugar de diálogo entre diversos escritores de Hispanoamérica. De ahí la relevancia del tema español durante la década de los años cuarentas. La revista marca toda una época en la historia de la cultura y la política costarricense y española la cual está todavía por descubrirse. Sin duda, los textos examinados representan especial interés para la historia del exilio español en Centroamérica.

\section{Conclusiones}

Al reconstruir el panorama político y cultural entre España y Costa Rica durante la década de los años cuarentas se descubre un esquema político muy polarizado: por un lado, la postura de neutralidad con respecto al conflicto peninsular, y, por otro, la actitud que en la práctica tomaron los distintos gobierno costarricenses. Sin embargo, y pese al limitado número de exiliados que llegó al país centroamericano, cada uno de ellos disfrutó de una estabilidad laboral y económica.

La llegada de los refugiados políticos -Víctor Lorz, Rafael de Buen Lozano, Rafael Ruano Riesgo y León Felipe- a Costa Rica, contó con una acogida favorable en las páginas de Repertorio Americano. La revista se consolidó como una de las plataformas más importantes en Centroamérica a favor de la causa republicana en el exilio. 
En lo que concierne a las colaboraciones de los desterrados, se observa una constancia en sus posturas políticas. En los ensayos políticos se aprecia la preocupación por el devenir de la Segunda Guerra Mundial, el análisis de las causas de la derrota de la República, la crítica constante al régimen franquista $y$, aunque en menor medida, la fe en la política e ideología de la URSS. Asimismo, hemos hecho especial énfasis en el homenaje que Repertorio Americano brindó al poeta León Felipe a su llegada a Costa Rica.

Pese a que las cuatro figuras que estudiamos en este ensayo continuaron su peregrinación por distintos países de Centroamérica, el Caribe y México, sin duda, su presencia en Costa Rica marca un hito fundamental para entender las dinámicas del éxodo español en América Latina.

En el transcurso de nuestro análisis intentamos señalar algunos de los rasgos más sobresalientes de las reflexiones políticas realizadas por cada uno de los refugiados españoles. Las colaboraciones de los exiliados en la revista costarricense Repertorio Americano constituyen un elemento fundamental para reconstruir y entender el panorama político y cultural del destierro español en Costa Rica. Pese a que el tema del exilio republicano en las páginas de Repertorio America- no es muy amplio y complejo, el análisis presentado espera aportar a la poca bibliografía que actualmente existe sobre el tema.

\section{Referencias bibliográficas}

Abellán, J. L. (1996). La revista España Peregrina como paradigma del exilio español de 1939. Archipiélago: Cuadernos de crítica de la cultura, 26-27, pp. 119-124.

Agüero Chaves, A. (1946). Exhortación. Repertorio Americano, No. 1003, p. 234.

Aguilar Machado, F. (1946). León Felipe. Repertorio Americano, $\mathrm{N}^{\circ} 1003$, p.232.

Amo, J. y Shelby, C. (1959). La obra impresa de los intelectuales españoles en América (1936-1945). California: Standford University Press.

Caudet, F. (1992). El exilio republicano en México. Las revistas literarias (1939. 1971). Madrid: Fundación Banco Exterior.

De Buen Lozano, R. (1942). El carácter de la actual contienda (2). Repertorio Americano, № 931, pp. 45-46.

Del Camino, J. (1939). Estamos con la Buena causa, que es la de Chile, desde luego. Repertorio Americano. № 873, p. 272.

Faber, S. (2005). Silencios y tabues del exilio español en México: Historia oficial vs. historia oral. Espacio, 
tiempo y forma, Serie V [Historia Contemporánea], pp. 373-389

Felipe Camino, L. Esta carta... Repertorio Americano, No 1003, p. 233.

Gamboa, E. (1946). León Felipe. Repertorio Americano, No 1003, p. 232.

González Neira, A. (2010). Prensa del exilio republicano 1936-1977. Santiago de Compostela: Andavira Editora.

Lorz y Lizárraga, V. (1939a). Para que se rasque. Repertorio Americano, $\mathrm{N}^{\circ}$ 868, p. 187.

$\left(1939^{\mathrm{b}}\right)$. Al vagar de una pluma bohemia. Repertorio Americano, No 869, pp. 196-197.

. $\left(1942^{\mathrm{a}}\right)$. Las golondri-

nas de Bécquer. Repertorio Americano, No 933, pp. 70-71.

(1942 b). Recuerdos y

esperanzas. Repertorio Americano, $\mathrm{N}^{\circ}$ 936, pp. 122-123.

(1943). Ocios menta-

les. Por el tema ruso a los temas eternos", Repertorio Americano, número 965, p. 196/ p. 206.

(1944). Mi profesión

de fe. Repertorio Americano, No 978, pp. 177-179.

(1950a). Ocios menta-

les. Repertorio Americano, No 1109 , pp. 149-151.

. $\left(1950^{\mathrm{b}}\right)$. Ocios menta-

les. Repertorio Americano, No 1115, pp. 250-252.
Odio González, E. (1939). Un sensible desacierto del Gobierno de Costa Rica, frente al incidente diplomático chileno-español. Repertorio Americano, No 872, pp. 244-245.

Oliva Medina, M. (2008 ${ }^{\mathrm{a}}$. Historia de Repertorio Americano (1919-1958). Revista de Comunicación, (17)29, pp. 31-43.

. $\left(2008^{\mathrm{b}}\right)$, Los intelectuales y las letras centroamericanas sobre la Guerra Civil española. México: UNAM/CIALC.

Pardo Sanz, R. M. (1990). América Latina y la guerra civil española. Costa Rica: un estudio de caso. Espacio, tiempo y forma, 3, pp. 155-176.

Rodríguez, C. (1946). León Felipe Camino. Repertorio Americano, $\mathrm{N}^{\circ}$ 1003, p. 233.

Rojo, G. y Valender, J. (1999). Las Espanas: historia de una revista del exilio. México: El Colegio de México.

Ruano Riesgo, R. (1943). La guerra de España y la situación política europea. Repertorio Americano, No 961, pp. 144-145.

Tarracena, A. (2015). Rafael de Buen Lozano: el periplo americano de un exiliado republicano español. Cuadernos Intercambio sobre Centroamérica y el Caribe, 12(2), pp. $101-115$. 